\title{
Circuitry Underlying Regulation of the Serotonergic System by Swim Stress
}

\author{
Michelle Roche, Kathryn G. Commons, Andrew Peoples, and Rita J. Valentino \\ The Children's Hospital of Philadelphia, Philadelphia, Pennsylvania 19104
}

The dorsal raphe nucleus (DR)-serotonin (5-HT) system has been implicated in depression and is dramatically affected by swim stress, an animal model with predictive value for antidepressants. Accumulating evidence implicates the stress-related neuropeptide corticotropin-releasing factor (CRF) in the effect of swim stress on this system. This study investigated neural circuits within the DR that are activated by swim stress as revealed by neuronal expression of the immediate early gene, c-fos. Swim stress increased c-fos expression in the dorsolateral subregion of the DR. The majority of c-fos-expressing neurons were doubly labeled for GABA ( $85 \pm 5 \%$ ), whereas relatively few were immunolabeled for 5 -HT $(4 \pm 1 \%)$, glutamate $(0.5 \pm 0.3 \%)$ or calbindin $(1.5 \pm 0.3 \%)$. Dual immunohistochemical labeling revealed that c-fos-expressing neurons in the dorsolateral DR were enveloped by dense clusters of CRF-immunoreactive fibers and also contained immunolabeling for CRF receptor, suggesting that c-fos-expressing neurons in the DR were specifically targeted by CRF. Consistent with this, the CRF receptor 1 antagonist, antalarmin, prevented swim-stress-elicited c-fos expression in the dorsolateral DR. Together with previous findings that both swim stress and CRF decrease 5-HT release in certain forebrain regions, these results suggest that swim stress engages CRF inputs to GABA neurons in the dorsolateral DR that function to inhibit 5-HT neurons and 5-HT release in the forebrain. This circuitry may underlie some of the acute behavioral responses to swim stress as well as the neuronal plasticity involved in long-term behavioral changes produced by this stress.

Key words: dorsal raphe nucleus; serotonin; corticotropin-releasing factor; GABA; c-fos; antalarmin; swim stress

\section{Introduction}

Stress has been implicated in many medical and psychiatric disorders (Elenkov and Chrousos, 1999; Chrousos, 2000; Habib et al., 2001). Although the acute stress response is adaptive, repeated, chronic, or a single severe stress can initiate long-term neuronal changes that may underlie stress-related pathophysiology (Dallman et al., 1992; De Goeij et al., 1992). One experimental stress that results in long-term behavioral changes is swim stress, and this phenomenon is a key element of the forced-swim test, a validated screen for antidepressant activity (Porsolt et al., 1977; Porsolt et al., 1978). On initial exposure to swim stress, rats exhibit both active (e.g., swimming) and passive (e.g., floating) behaviors. During a second exposure ( $24 \mathrm{hr}$ to 2 weeks later), the pattern changes such that active behavior is diminished and passive behavior predominates. Like certain other experimental strategies that model aspects of depression, this model involves a stress-induced bias toward passive behavior that is sensitive to antidepressant treatments (Maier and Jackson, 1979; Weiss et al., 1981). Sensitivity to diverse antidepressant treatments suggests that the neural plasticity that underlies the behavioral change is a common target of antidepressant agents.

The dorsal raphe nucleus (DR)-serotonin (5-HT) system is dramatically affected by swim stress and has been implicated in

\footnotetext{
Received May 15, 2002; revised Nov. 1, 2002; accepted Nov. 12, 2002.

This work was supported by United States Public Health Service Grants MH58250, DA00463, and MH02006 and by a National Alliance for Research on Schizophrenia and Depression Distinguished Investigator Award (R.J.V.). We thank Vincent Bey and K. Ryan Connolley for expert technical assistance.

Correspondence should be addressed to Rita J.Valentino, The Children's Hospital of Philadelphia, 402C Abramson Pediatric Research Center, 34th and Civic Center Boulevard, Philadelphia, PA 19104. E-mail: valentino@email.chop.edu.

M. Roche's present address: Department of Neuropharmacology, National University of Ireland, Galway, Ireland. Copyright $\odot 2003$ Society for Neuroscience $\quad 0270-6474 / 03 / 230970-08 \$ 15.00 / 0$
}

affective disorders. Swim stress produces robust decreases in 5-HT release in certain forebrain targets of the DR (Kirby et al., 1995, 1997; Kirby and Lucki, 1997). A correlation between inhibition of 5-HT release and active coping in the swim test implicates this neurochemical effect in the behavioral response to swim stress (Kirby and Lucki, 1997).

Serotonin neurons within the DR are topographically organized such that different subregions have distinct afferent inputs and efferent projections, suggesting that they are differentially engaged and subserve distinct functions (O'Hearn and Molliver, 1984; Molliver, 1987; Jacobs and Azmitia, 1992). A goal of this study was to localize and neurochemically identify neurons within the DR that are engaged during an initial exposure to swim stress. Immunohistochemical methods were used to localize the transcription factor c-fos within the DR, and dual immunolabeling was used to neurochemically identify c-fos-expressing neurons.

A role for the stress-related neuropeptide corticotropinreleasing factor (CRF) in the effects of swim stress on the DR5 -HT system is suggested by studies demonstrating that CRF mimics the effects of swim stress on 5-HT release (Price and Lucki, 2001) and that the effects of swim stress on 5-HT release in the lateral septum are prevented by a CRF antagonist (Price et al., 2002). To determine whether CRF afferents to the DR target neurons that are activated during swim stress, c-fos immunolabeling was combined with immunolabeling for either CRF or the CRF receptor (CRF-R). In addition, the ability of a CRF antagonist to prevent swim-stress-induced c-fos expression in the DR was examined. Finally, to investigate a role for c-fos-expressing DR neurons in adaptation to swim stress, c-fos profiles were quantified after a second exposure to swim stress. 


\section{Materials and Methods}

Subjects. Adult male Sprague Dawley rats (250-300 gm; Taconic Farms, Germantown, NY) were housed three per cage on a $12 \mathrm{hr}$ light/dark schedule in a temperature-controlled $\left(22^{\circ} \mathrm{C}\right)$ colony room. Rats were given ad libitum access to standard rat chow and water. Care and use of animals were approved by the Stokes Institute of the Children's Hospital of Philadelphia Institutional Animal Care and Use Committee and performed in accordance with the National Institutes of Health Guide for the Care and Use of Laboratory Animals. All efforts were made to minimize animal suffering, and only the number of animals necessary to produce reliable scientific data were used.

Swim stress. The procedures used for swim stress were identical to those described previously by others (Porsolt et al., 1977, 1978; Borsini and Meli, 1988; Borsini et al., 1989; Detke et al., 1995). Rats were handled for 4 consecutive days before swim stress. On the fifth day, rats were divided into control and swim groups randomly. For the swim, rats were placed in a cylindrical glass tank $(46 \mathrm{~cm}$ high $\times 20 \mathrm{~cm}$ diameter $)$ filled with water $\left(25 \pm 1^{\circ} \mathrm{C}\right)$ to a depth of $30 \mathrm{~cm}$ for $15 \mathrm{~min}$. The $30 \mathrm{~cm}$ depth allowed rats to swim or float without having their tails touch the bottom of the tank. Immediately after the $15 \mathrm{~min}$ swim, rats were removed from the tank, towel dried, and put in a warming cage $\left(37^{\circ} \mathrm{C}\right)$ that contained a heating pad covered with towels for $15 \mathrm{~min}$. Rats were then returned to their home cage. Nonswim control animals were handled briefly. Experimental groups were matched such that a swim-stress rat and control rat were perfused on the same day and tissue was processed in parallel. Some rats were pretreated $30 \mathrm{~min}$ before swim stress with either the selective CRF-R1 antagonist antalarmin $(20 \mathrm{mg} / \mathrm{kg}$, i.p.) or vehicle ( $1 \mathrm{ml} / \mathrm{kg}$, i.p.).

To examine the effects of a second exposure to swim stress on c-fos expression, rats were divided into four groups ( $n=5$ rats per group); one group was handled on days 1 and $2(\mathrm{HH})$, one group was handled on day 1 and exposed to a $5 \mathrm{~min}$ swim stress on day 2 (HS), one group was exposed to a $15 \mathrm{~min}$ swim stress on day 1 and handled on day $2(\mathrm{SH})$, and one group was exposed to a $15 \mathrm{~min}$ swim stress on day 1 and a $5 \mathrm{~min}$ swim stress on day 2 (SS). Rats were anesthetized and perfused $2 \mathrm{hr}$ after the start of the manipulation (swim or handling) on day 2.

Immunohistochemistry. Rats were deeply anesthetized with sodium pentobarbital ( $100 \mathrm{mg} / \mathrm{kg}$, i.p.) $105 \mathrm{~min}$ after the end of the $15 \mathrm{~min}$ swim or $115 \mathrm{~min}$ after the $5 \mathrm{~min}$ swim and transcardially perfused with $100 \mathrm{ml}$ of heparinized saline solution, followed by $500 \mathrm{ml}$ of $4 \%$ paraformaldehyde in $0.1 \mathrm{M}$ phosphate buffer $(\mathrm{PB})\left(4^{\circ} \mathrm{C}\right), \mathrm{pH}$ 7.4. For tissue processed for glutamate immunoreactivity, the fixative consisted of $4 \%$ glutaraldehyde in $0.1 \mathrm{M}$ PB. Brains were removed and stored in the same fixative solution for $90 \mathrm{~min}\left(4^{\circ} \mathrm{C}\right)$ and then overnight in a solution of $20 \%$ sucrose in $0.1 \mathrm{M} \mathrm{PB}$ containing $0.1 \%$ sodium azide $\left(4^{\circ} \mathrm{C}\right)$. Brains were rapidly frozen with $\mathrm{CO}_{2}$, and $30 \mu \mathrm{m}$ coronal sections were cut on a cryostat. The sections were collected in $0.1 \mathrm{M} \mathrm{PB}, \mathrm{pH}$ 7.4.

Before immunohistochemical labeling, sections were incubated for 20 min in either (1) $0.75 \% \mathrm{H}_{2} \mathrm{O}_{2}$ in $\mathrm{PB}$ for paraformaldehyde-fixed tissue or (2) $1 \%$ sodium borohydride in PB for glutaraldehyde-fixed tissue, followed by several rinses in $\mathrm{PB}$. All primary antisera were diluted in $0.1 \mathrm{M}$ PBS containing $0.3 \%$ Triton X-100 (PBST), $0.04 \%$ bovine serum albumin (BSA), and $0.1 \%$ sodium azide and incubated with the tissue for $2-3$ $\mathrm{d}$ at $4^{\circ} \mathrm{C}$. Secondary antisera (Jackson ImmunoResearch, West Grove, PA) diluted in PBST-BSA were raised in donkey and had minimal crossreactivity to nontarget species. Sections were rinsed several times in PBST between incubations.

c-fos immunoreactivity was assessed by incubating sections in rabbit anti c-fos antisera (Oncogene Research Products, Cambridge, MA) at a dilution of 1:20,000. The primary antiserum is directed against residues 4-7 of human c-fos. Sections were incubated in biotinylated donkey anti-rabbit antiserum (1:200) for $90 \mathrm{~min}$, followed by avidin-biotin complex (1:600; ABC Elite Kit; Vector Laboratories, Burlingame, CA) for $90 \mathrm{~min}$ at room temperature. Sections were then immersed in $0.02 \%$ 3,3'-diaminobenzidine- $4 \mathrm{HCl}$ (Sigma, St Louis, MO) containing $0.01 \%$ $\mathrm{H}_{2} \mathrm{O}_{2}$ in $\mathrm{PB}$ for $10-15$ min for a brown reaction product that was terminated by rinses in $\mathrm{PB}$.

Before dual labeling, sections were incubated in $0.75 \% \mathrm{H}_{2} \mathrm{O}_{2}$ in $\mathrm{PB}$ for 20 min followed by rinses in PBS. This was followed by incubation in rabbit anti-5-HT (1:10,000; Incstar, Stilwater, MN), mouse antiglutamate (1:1000; Chemicon, Temecula, CA), mouse anti-calbindin (1: 1000; Sigma), or rabbit anti-CRF antiserum (1:8000; Dr. W. Vale, The Salk Institute, San Diego, CA). Sections were rinsed in PBST-BSA and processed as described above for c-fos using the ABC elite kit. After rinsing, the immunolabeling was visualized using the Vector SG peroxidase substrate kit (Vector Laboratories) yielding a blue reaction product.

Sections were mounted on glass gelatinized slides, dehydrated in a series of alcohols, cleared with xylene, and coverslipped with Permount (Sigma). Photomicrographs were taken using a Leica (Bannockburn, IL) microscope and a Fuji (Tokyo, Japan) S1 Pro digital camera.

For immunofluorescent detection of c-fos and CRF-R, sections were incubated in a mixture of rabbit anti c-fos antisera (1:2000; Oncogene Research Products) and goat anti-CRF-R1 (1:1000; Santa Cruz Biotechnology, Santa Cruz, CA). The CRF-R1 antiserum identifies a single protein band by Western blot analysis, and immunohistochemical labeling is diminished by preabsorption with the antigenic peptide (Chen et al., 2000). According to the manufacturer's specifications, this antiserum may also detect CRF-R2. After rinsing in PBST-BSA, sections were incubated in solution containing tetramethylrhodamine isothiocyanate antirabbit (1:200; Jackson ImmunoResearch) and FITC anti-goat (1:200; Jackson ImmunoResearch). For immunofluorescent detection of c-fos and GABA, sections were incubated with a mixture of the same c-fos antisera and anti-GABA antisera raised in guinea pig (1:1000; Protos Biotech, New York, NY). c-fos was detected using a RITC-conjugated secondary antisera, whereas GABA was detected using the avidin-biotin immunoperoxidase method (ABC elite kit) with NEN tyramide kit FITC substrate. Sections were subsequently rinsed, mounted on gelatinized glass slides, and coverslipped using Vectashield (Vector Laboratories).

For triple immunofluorescence labeling of GABA, c-fos, and CRF-R, tissue from three rats was first dually labeled for GABA as described previously and for CRF-R using RITC-conjugated anti-rabbit antisera. Tissue was then rinsed and incubated in the same c-fos antisera and subsequently visualized with aminomethylcoumarin acetate-conjugated anti-rabbit antisera. The use of two antisera raised in rabbit produced little cross reactivity and the individual labels were easily distinguished by differential subcellular localization.

Immunofluorescent labeling was visualized using a Leica microscope, and images were captured with a Kodak 1400 digital camera (Princeton Instruments, Trenton, NJ) using Open Lab software (Improvision, Coventry, UK).

Data analysis. c-fos-immunolabeled profiles were counted in the dorsolateral, dorsomedial, and ventromedial subregions of the DR from at least three sections per rat from five stressed and five control rats. The area defined by each subregion was based on the extent of the cellular groups comprising the regions and specific landmarks (see Fig. 1). The rostrocaudal extent of the DR in which quantification was done corresponded to plates 49-52 (Paxinos and Watson, 1998). The fasiculus served as the ventral border of the region defined as the ventromedial subregion. The presence of specific blood vessels and the base of the aqueduct defined the lateral and dorsal boundaries of the dorsolateral subregions, respectively. Figure 1 indicates the area in which profiles were counted for each region. The plots shown in Figure 1 were generated by capturing representative images of c-fos immunolabeling from sections from handled (control) and swim-stressed rats. All detectable c-fosimmunolabeled cells were then plotted, and section boundaries were indicated. When counting sections in the dorsolateral region, each side represented an individual determination. In addition to the DR, c-fosimmunoreactive profiles were quantified in the locus ceruleus (LC) of the same cases (at least three sections per rat). The mean number of immunolabeled profiles per section was determined for each rat within a group, and these individual means were averaged to give group means that were compared using a factorial ANOVA with Scheffe's post hoc test.

For counts of double-labeled neurons (i.e., c-fos and 5-HT, GABA, glutamate, calbindin, or CRF-R), at least $100 \mathrm{c}$-fos-immunolabeled profiles were counted in at least four sections from each of three rats in which immunolabeling for both antigens was distinct. For this analysis, cells 
were either analyzed directly or analyzed from digitally captured images. The percentage of dual-labeled neurons (out of total c-fosimmunoreactive profiles) was determined for each rat and averaged across rats. For analysis of coexistence of three immunolabels, individual high-magnification fields were digitally captured, pseudocolored, merged, and examined. Fields were captured from a total of nine sections from three rats in which immunolabeling for all three antigens was detectable.

Drugs. Antalarmin (Dr. Kenner Rice, Laboratory of Medicinal Chemistry, National Institutes of Health/National Institute of Diabetes and Digestive and Kidney Diseases, Bethesda, MD) was dissolved in a solution containing 5\% ethanol and 5\% cremaphor.

\section{Results \\ Swim stress induces c-fos in the dorsolateral DR}

Tissue was obtained from eight rats that were subjected to swim stress and eight matched controls. The distribution of c-fos immunolabeling in rats subjected to swim stress was similar to that reported previously (Duncan et al., 1993; Cullinan et al., 1996). For example, c-fos-immunoreactive profiles were numerous in the LC, dorsolateral parabrachial nucleus, lateral habenula, paraventricular nucleus of the hypothalamus, and lateral septum of swim-stressed rats. In contrast, c-fos expression was absent or minimal in these regions in handled rats. Within the DR, c-fosimmunoreactive profiles were most prevalent in the dorsolateral subregion (Fig. 1, also see Fig. 4A). The mean number of c-fosimmunoreactive profiles per section in this subregion was $50 \pm 2$ in swim-stressed rats ( $n=24$ sections from five rats) versus $17 \pm 1$ in matched controls ( $n=24$ sections from five rats) (Fig. 2). Although the mean numbers of c-fos-immunoreactive profiles in the dorsomedial or ventromedial subregions were substantially less than in the dorsolateral subregion, these were statistically higher in swimstressed rats versus controls. Thus, in the dorsomedial DR, the mean number of c-fos-immunoreactive profiles per section in swimstressed versus control rats was $15 \pm 1$ and $6 \pm 1$, respectively $(n=$ 12 sections from five rats for both groups) $(p<0.0001)$. In the ventromedial region, the mean number of c-fos-immunoreactive profiles per section in swim-stressed versus control rats was $16 \pm 2$ and $9 \pm 1(n=12$ sections from five rats), respectively ( $p<$ $0.01)$. c-fos expression was also quantified in the LC. Swim stress resulted in a statistically significant increase in c-fosimmunoreactive profiles per section in this nucleus (mean, $56 \pm 4)$ compared with handling $(2 \pm 0.4)$ (Fig. 2).

\section{Neurochemical identity of c-fos-expressing neurons}

To identify the neurochemical phenotype of neurons in the dorsolateral DR that express c-fos in response to swim stress, sections were dually immunolabeled for c-fos and 5-HT, glutamate, GABA, or calbindin. Few 5-HT neurons contained c-fos-immunolabeled nuclear profiles (Fig. 3A, Table 1). An even smaller number of neurons were doubly labeled for $\mathrm{c}$-fos and glutamate or $\mathrm{c}$-fos and calbindin (Fig. 3B,C, Table 1). In contrast, a substantial number of c-fos-immunoreactive profiles were observed within neurons that

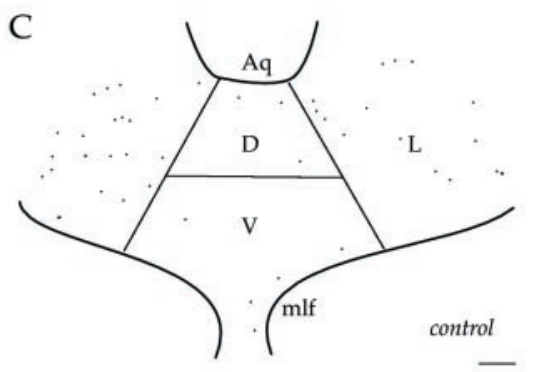

$\mathrm{D}$

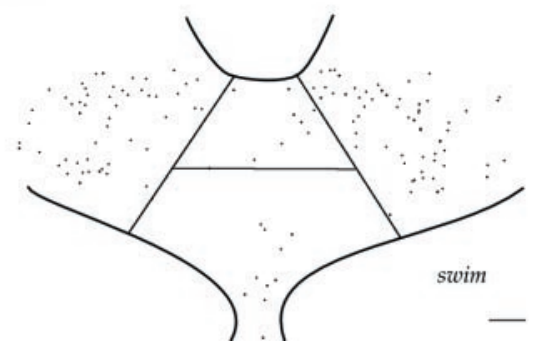

Figure 1. Swim stress robustly increases c-fos expression in cells in the dorsolateral subregion of the DR. Sections from handled conts $(A)$ and swim-stressed rats $(B)$ are dually immunolabeled for 5 -HT (blue) and c-fos (brown). Clusters of 5-HT-containing that were singly labeled for c-fos are shown. Swim stress produced an increase in c-fos profiles in all subregions of the DR; however, the increase was most notable in the dorsolateral subregion (L). Scale bars, $120 \mu \mathrm{m}$.

were GABA-immunoreactive (Fig. 3D,E, Table 1). The mean percentages of c-fos-immunolabeled nuclear profiles that were within neurons containing these neurochemical markers are given in Table 1.

\section{c-fos neurons are targeted by CRF}

Previous studies described a topographical distribution of CRF fibers within the DR, including a dense innervation of the dorsolateral region at caudal to mid-levels of the DR (Kirby et al., 2000; Valentino et al., 2001). CRF is present within axon terminals that synapse onto somatodendritic processes within this region (Valentino et al., 2001). In sections from swim-stressed rats that were doubly immunolabeled for $\mathrm{c}$-fos and CRF, the c-fos profiles in the dorsolateral region were found to lie within the CRF terminal area (Fig. 4A,B). Moreover, c-fos-immunolabeled profiles were often surrounded by dense clusters of CRF varicose processes reminiscent of basket-cell-like innervation by CRF-containing axon terminals (Fig. $4 B, C$ ). Consistent with this, double immunolabeling for $\mathrm{c}-$ fos and CRF-R revealed that c-fosimmunolabeled profiles were often associated with CRF-R immunolabeling (Fig. 4D, Table 1).

Some tissue was processed for triple immunolabeling to identify c-fos, GABA, and CRF-R to confirm that CRF-R coexisted with c-fos in GABA-containing cells. Figure 5 shows examples of several GABA neurons in the dorsolateral DR that express c-fos and also exhibit CRF-R immunolabeling after swim stress. Although coexistence of multiple immunolabels is subject to substantial underdetection, triple-labeled cells were commonly observed. Five to nine triple-labeled neurons could be distinguished in each high-power image of the dorsolateral DR. Of a total of 200 c-fos-immunoreactive profiles examined in these highmagnification captured images, 73 (36.5\%) were also clearly labeled for both GABA and CRF-R. 


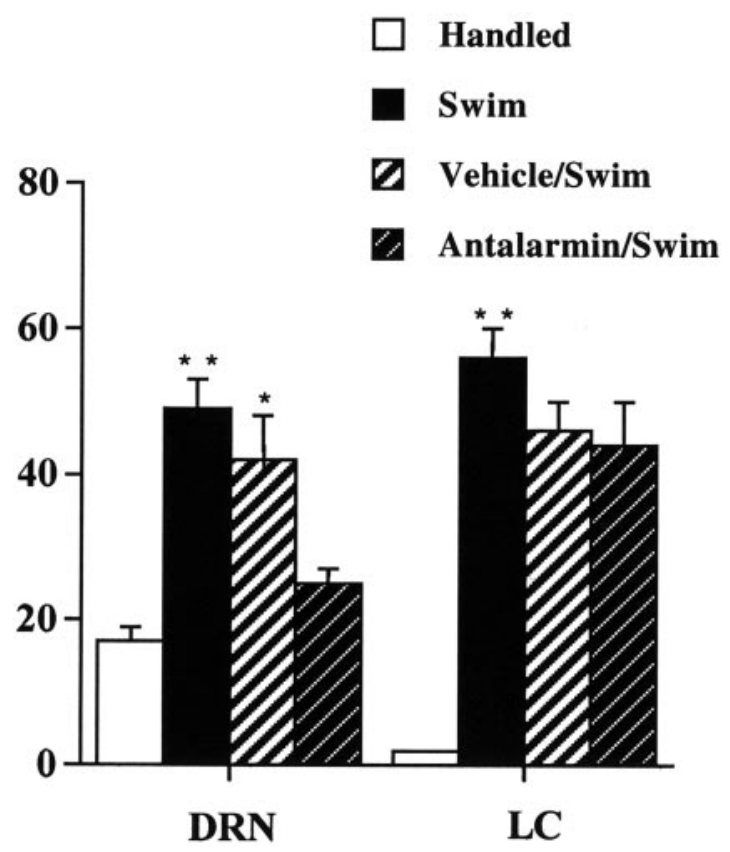

Figure 2. Quantification of swim stress-induced c-fos expression in the dorsolateral dorsal raphe nucleus $(D R N)$ and $L C$ and effects of antalarmin. The bars represent the mean number of c-fos-immunolabeled profiles per section for different groups. As described in Materials and Methods, a mean was determined for individual rats, and a group average was calculated from these means. The groups were composed of five rats that were handled (open bars; $n=24$ total sections), five rats exposed to swim stress (solid bars; $n=24$ total sections), six rats pretreated with vehicle before swim (black hatched bars; $n=76$ total sections), and six rats pretreated with antalarmin before swim (white hatched bars; $n=66$ total sections). The factorial ANOVA comparing DR data revealed a group effect $\left(F_{(3,18)}=15.5 ; p<0.001\right)$. Post hoc Scheffe's tests revealed statistically significant differences between swim and handled ( $p<0.002)$, swim and antalarmin $(p<0.005)$, vehicle/swim and handled $(p<0.002)$, and vehicle and antalarmin $(p<0.05)$ groups. In contrast, the swim versus vehicle/swim comparison and handled versus antalarmin/swim comparison did not reveal statistically significant differences. The factorial ANOVA comparing $\mathrm{LC}$ data revealed a group effect $\left(F_{(3,16)}=29.7 ; p<0.0001\right)$. Post hoc Scheffe's tests revealed statistically significant differences between the handled group and all other groups $(p<0.0001)$. The swim-stress groups were not statistically different from one another, regardless of pretreatment. ${ }^{* *} p<0.0002$ compared with handled; ${ }^{*} p<0.05$ compared with vehicle.

\section{CRF-R1 antagonist prevents swim-stress-induced c-fos expression}

To determine whether c-fos induction in the dorsolateral DR by swim stress was dependent on endogenous CRF, rats were administered the selective CRF-R1 antagonist antalarmin (20 mg/ kg, i.p.) (Webster et al., 1996) or vehicle 30 min before swim stress. The mean number of c-fos-immunolabeled profiles in rats pretreated with vehicle before swim stress was not significantly different from that seen in rats exposed to swim stress alone $(p=0.2)$ (Fig. 2). In contrast, the mean number of $c$-fos-immunolabeled profiles was substantially reduced in rats pretreated with antalarmin compared with either vehicletreated rats $(p<0.05)$ or swim-stress rats that were not pretreated $(p<0.005)$. In addition, the mean number of $c$-fos profiles in rats pretreated with antalarmin before swim stress was not significantly different from that seen in rats that were handled ( $p=0.6$ ), suggesting that antalarmin pretreatment completely prevented this effect of swim stress. In contrast to its effects on c-fos expression in the DR, pretreatment with antalarmin did not alter c-fos expression in the LC (Fig. 2).
Effects of previous swim stress on c-fos induction in the dorsolateral DR by a subsequent swim

Figure 6 shows the effect of a 5 min swim stress or handling on c-fos expression in the dorsolateral DR of rats that were either handled or exposed to swim stress $(15 \mathrm{~min}) 24 \mathrm{hr}$ previously. A two-factor ANOVA revealed a significant effect of treatment on day $2\left(F_{(1,16)}=5 ; p<0.05\right)$, indicating that a 5 min swim stress on day 2 induced c-fos expression. However, although the mean number of c-fos profiles tended to be less in rats with a previous history of swim stress (SS), there was no effect of treatment on day 1 .

\section{Discussion}

The present study demonstrated that acute exposure to swim stress induced c-fos expression in GABAergic neurons in the dorsolateral subregion of the DR. Convergent findings suggest that this resulted from activation of CRF-R1 receptors. Thus, c-fosexpressing neurons were targeted by CRF axon terminals and exhibited CRF-R1 immunolabeling. Furthermore, CRF-R1 was present on GABA-containing neurons that expressed c-fos in this area. Importantly, administration of a selective CRF-R1 antagonist prevented swim-induced c-fos expression. Given that swim stress inhibits 5-HT release in certain terminal regions of the DR (Kirby et al., 1995; Kirby and Lucki, 1997), and that this is prevented by administration of a CRF antagonist (Price et al., 2002), the present results suggest that swim stress engages CRF afferents that target and activate GABA neurons in the dorsolateral DR, thereby inhibiting this serotonergic system. This mechanism may underlie aspects of acute behavioral responses to swim stress. The finding that previous exposure to swim stress, which prevents the ability of a subsequent swim or CRF to decrease 5-HT release (Price et al., 2002), did not alter c-fos induction by a second swim suggests that the neural adaptation occurs at a site distal to the GABA neuron.

\section{Technical considerations}

The present interpretations rely on the assumption that c-fos immunolabeling is a marker of neuronal activation. Although this is supported by numerous studies (Dragunow and Faull, 1989), the lack of c-fos expression does not preclude neuronal activation that has distinct transcriptional consequences. Therefore, it is possible that swim stress activated neurons within the DR that were not identified here.

\section{Circuitry underlying effects of swim stress on the DR-5-HT system}

Acute swim stress produces robust long-lasting decreases in 5-HT extracellular levels in the lateral septum and amygdala, forebrain targets of the DR (Kirby et al., 1995, 1997; Kirby and Lucki, 1997). Convergent findings implicate CRF in these inhibitory effects. CRF densely innervates the DR (Valentino et al., 2001), and CRF receptor binding and receptor mRNA are prevalent in this region (Rominger et al., 1998) (Chalmers et al., 1995). CRF administered into the DR inhibits the neuronal discharge rate in vivo (Kirby et al., 2000) and mimics the inhibitory effect of swim stress on 5-HT release (Price et al., 1998, 2002; Price and Lucki, 2001). Importantly, inhibition of 5-HT release by swim stress is prevented by previous administration of a CRF antagonist (Price et al., 2002). The present findings now provide a putative neural circuit underlying the effects of swim stress on this system. It is hypothesized that swim stress engages CRF inputs to GABAergic neurons in the dorsolateral DR, which in turn 
inhibit 5-HT neuronal activity and 5-HT release in certain forebrain regions. Indeed, DR 5-HT cells are under tonic inhibitory control by both $\mathrm{GABA}_{\mathrm{A}}$ (Tao and Auerbach, 2000) and $\mathrm{GABA}_{\mathrm{B}}$ receptors (Abellan et al., 2000; Varga et al., 2001).

Several findings link inhibition of 5-HT release in the lateral septum with active coping during swim stress. For example, during the initial exposure to swim, at a time when extracellular levels of 5-HT in the lateral septum are decreased, a combination of active (swimming, climbing) and passive (e.g., immobility) behaviors are observed (Porsolt et al., 1977, 1978; Detke et al., 1995; Kirby and Lucki, 1998). On subsequent exposure to swim stress, when the effect on 5-HT release is lost, passive behavior predominates (Kirby and Lucki, 1997, 1998). Importantly, extracellular levels of 5-HT in the lateral septum were positively correlated to immobility and negatively correlated to swimming (Kirby and Lucki, 1997, 1998). Finally, subchronic administration of the antidepressant fluoxetine between the initial and subsequent swim stress restored both the neurochemical response and the active component of the behavioral response (Kirby and Lucki, 1997). In addition to implying a link between the neurochemical (decreased 5-HT release) and behavioral (swimming) responses, these findings suggest that antidepressants target some component of the mechanisms involved in the neurochemical and behavioral adaptation.

A role for CRF in the neurochemical adaptation is supported by the findings that like the inhibitory effect of swim stress, the inhibitory effects of CRF on both 5-HT release and DR neuronal activity are lost in subjects with a history of previous swim stress (i.e., there is cross adaptation between swim stress and CRF administration in these subjects) (Price et al., 2002). Given the circuit supported by the present findings, the neurochemical adaptation could be attributable to (1) changes at the level of CRF receptor/transduction mechanisms resulting in an inability of CRF to activate GABA neurons, (2) changes at the level of GABA receptor/transduction mechanisms resulting in a loss of inhibition, or (3) induction of an excitatory effect on 5-HT neurons that opposes GABA-mediated inhibition. Although c-fos expression in the dorsolateral DR tended to be reduced in rats with a history of swim stress, this effect did not reach statistical significance. This finding suggests that plasticity at the level of the CRF receptor on GABA neurons cannot account for the neurochemical adaptation and supports alternative mechanisms, such as plasticity at the level of the GABA receptor on 5-HT neurons.
Table 1. Colocalization of c-fos with other neurochemical markers

\begin{tabular}{lc}
\hline Neurochemical marker & Percentage of c-fos neurons ${ }^{a}$ \\
\hline GABA & $85 \pm 5$ \\
5-HT & $4 \pm 0.7$ \\
Glutamate & $0.5 \pm 0.3$ \\
Calbindin & $1.5 \pm 0.3$ \\
CRF-R & $88 \pm 2$
\end{tabular}

${ }^{a}$ The percentage of dual-labeled neurons was determined as described in Materials and Methods.

\section{Relevance of the topography of c-fos expression in the DR}

CRF innervation of the DR is topographically organized such that at caudal to mid levels, CRF-immunoreactive fibers are most dense in the dorsolateral region (where c-fos expression was prevalent). Proceeding rostrally, CRF innervation shifts medially and ventrally (Kirby et al., 2000; Valentino et al., 2001). The relevance of this pattern lies in the topographical organization of efferent projections arising from the DR. Anatomical studies have provided evidence for an encephalotopy within the $D R$, such that different brain regions are targeted by distinct cell groups within the DR (Kohler and Steinbusch, 1982; O'Hearn and Molliver, 1984; Imai et al., 1986; Vertes, 1991). In this regard, the amygdala and lateral septum, two regions in which swim stress decreases 5 -HT release, receive a 5-HT innervation from the dorsolateral 

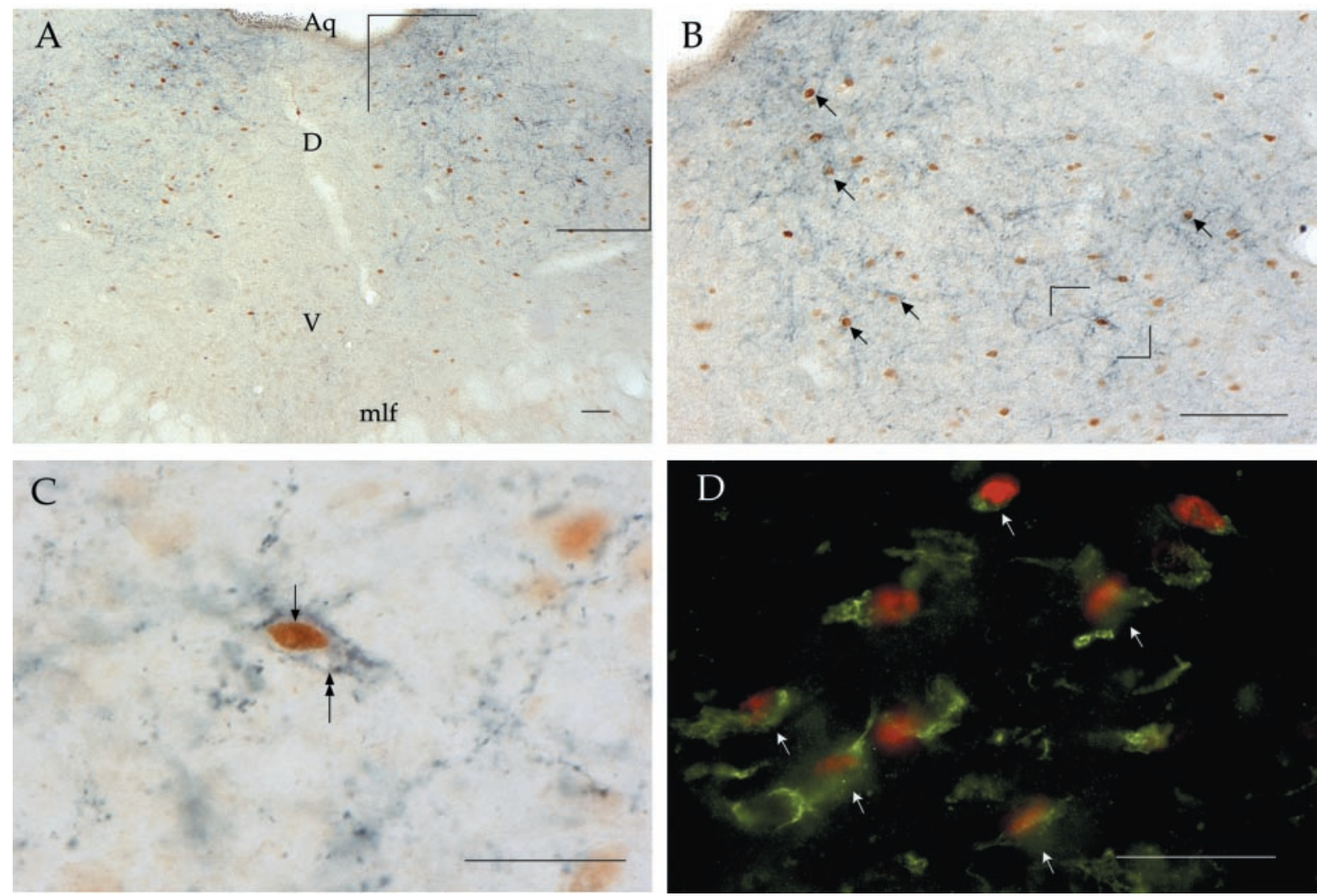

Figure 4. Relationship of CRF and CRF-R to neurons containing c-fos immunoreactivity after swim stress. A, Dual immunolabeling for CRF (blue) and c-fos (brown) reveals that c-fos-containing cells dorsolaterally are located in an area receiving rich innervation from CRF-containing axons. D, Dorsomedial DR; V, ventromedial DR; $A q$, aqueduct; $m l f$, medial longitudinal fasiculus. $B$, Higher magnification of the bracketed region in $A$ shows that several profiles with c-fos immunoreactivity appear to be surrounded by CRF-immunoreactive axons (arrows). C, Higher magnification of the bracketed area in B. c-fos immunoreactivity within a cell nucleus (arrow) is surrounded by a lucid cytoplasm. The entire cell appears to be enveloped by dense innervation from CRF-containing boutons (double-headed arrow). D, Dual immunofluorescence for c-fos (red) and CRF-R ( green) shows that c-fos-immunoreactive profiles visible after a swim stress contain CRF-R immunoreactivity (arrows). Scale bars: $A, B, 80 \mu \mathrm{m} ; C, D, 35 \mu \mathrm{m}$.

DR (De Olmos and Heimer, 1980; Kohler and Steinbusch, 1982; Imai et al., 1986).

The topographic organization of CRF innervation of the DR also suggests that CRF may act at distinct cell populations depending on the specific behavioral conditions. Consistent with this, recent evidence suggests a selective role for CRF within the ventral aspect of the caudal DR in learned helplessness (Hammack et al., 2002). In the present study, evidence is presented that GABAergic neurons in the dorsolateral DR have CRF-R; however, CRF-R immunoreactivity was not restricted to this cell population. The pattern of immunohistochemical labeling, as well as that of CRF-R mRNA expression (Chalmers et al., 1995), leaves open the possibility that CRF may also directly act on 5-HT cells, and this could be relevant for effects of CRF in the ventral DR.

Consistent with the hypothesis that CRF may act through different mechanisms in the ventral and dorsolateral DR, the types of cellular interactions between CRF terminals and processes in the DR within these subregions are distinct (Valentino et al., 2001). In the dorsolateral region, CRF terminals synaptically contact dendrites more frequently, and the majority of these synapses are asymmetric (excitatory). This stands in contrast to the ventromedial/interfasicular region, where associations between CRF terminals and non-CRF terminals are more prevalent and synaptic specializations between CRF terminals and nonlabeled dendrites are more often symmetric (inhibitory). The present findings predict that at least some of the dendrites contacted by CRF terminals in the dorsolateral DR are GABAergic.
Although swim stress increased expression of c-fos in LC neurons, this was not altered by previous administration of antalarmin. This is of interest given evidence for a role of CRF in LC activation by certain stressors (Page et al., 1993; Curtis et al., 1994; Lechner et al., 1997). The present findings suggest that CRF is not a primary mediator of LC activation during swim stress.

\section{Clinical significance}

A bias toward passive behavior in previously stressed animals that is sensitive to antidepressant treatments is a common feature of multiple experimental strategies that attempt to model depression, including learned helplessness, infant separation, and the forced-swim test (Maier and Jackson, 1979; Weiss et al., 1981; Thierry et al., 1984). Although passive coping may be appropriate and adaptive, the predominance and persistence of this strategy over active responses, which is a characteristic of depression (Hirschfeld et al., 1983; Chan, 1992; Snow-Turek et al., 1996; Bardwell et al., 2001; Muris et al., 2001) may be detrimental. The present findings suggest specific neural substrates and circuits that regulate the balance between different coping strategies.

The behavioral pattern elicited by swim stress has served as a valid model for predicting antidepressant activity (Porsolt et al., 1977, 1978; Borsini and Meli, 1988; Borsini et al., 1989; Detke et al., 1995). Identification of neurochemical substrates involved in the response provides rationale for the develop- 

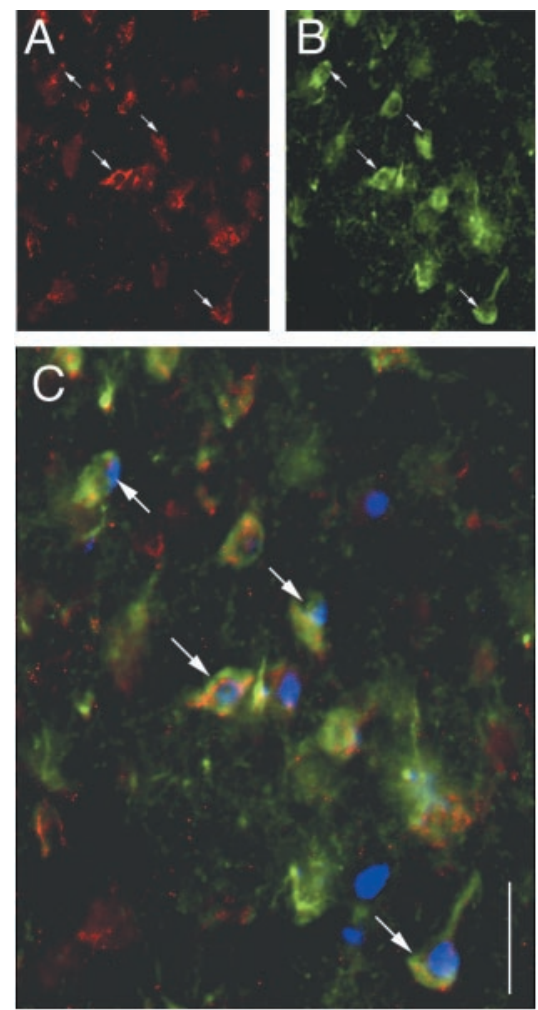

Figure 5. Cells dually immunolabeled for c-fos (blue) and GABA ( green) also contain labeling for CRF-R (red). A section illuminated to visualize CRF-R immunolabeling alone $(A)$, GABA immunolabeling alone $(B)$, and a merged image with $c-$ fos immunolabeling $(C)$ shows that many GABA and c-fos-immunolabeled neurons also contain (RF-R (arrows). Scale bar, $35 \mu \mathrm{m}$.

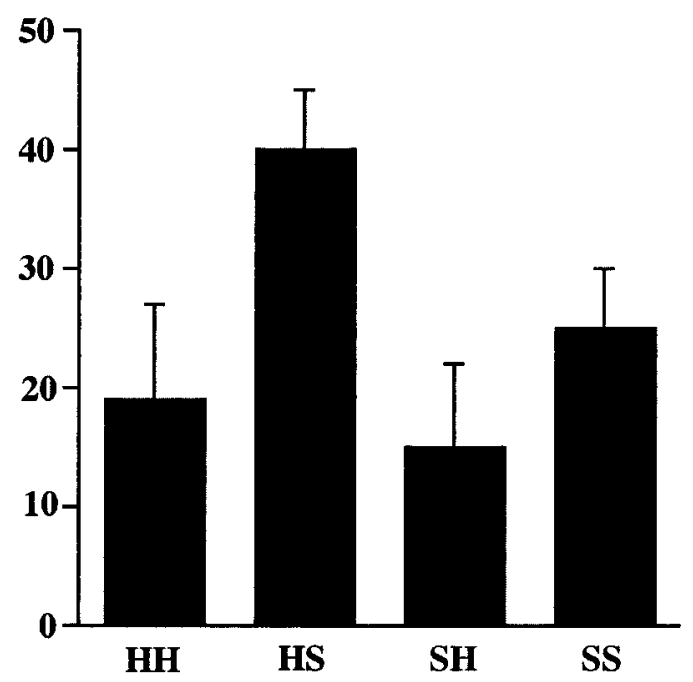

Figure 6. Quantification of c-fos expression in the dorsolateral DR of rats that were handled or exposed to swim stress ( $5 \mathrm{~min}$ ) $24 \mathrm{hr}$ after handling or a $15 \mathrm{~min}$ swim stress. As described in Materials and Methods, the groups included rats ( $n=5$ rats; 46 total sections) that were handled on days 1 and $2(\mathrm{HH})$, rats that were handled on day 1 and exposed to swim on day 2 ( $\mathrm{HS} ; n=5$ rats, 39 total sections), rats that were exposed to swim on day 1 and handled on day 2 ( $\mathrm{SH} ; n=5$ rats, 39 total sections), and rats that were exposed to swim on both days (SS; $n=5$ rats, 53 total sections). Bars represent the mean number of $c$-fos-immunolabeled neurons, and vertical lines indicate SEM. A twofactor ANOVA indicated a main effect of treatment on day $2\left(F_{(1,16)}=5 ; p<0.05\right)$.

ment of novel therapeutic agents. The present results suggest that in addition to classical agents used to treat these disorders, manipulation of CRF or GABA systems may be useful adjuncts.

\section{References}

Abellan MT, Adell A, Honrubia MA, Mengod G, Artigas F (2000) GABAB-R1 receptors in serotonergic neurons: effects on 5-HT output in rat brain. NeuroReport 11:941-945.

Bardwell WA, Ancoli-Israel S, Dimsdale JE (2001) Types of coping strategies are associated with increased depressive symptoms in patients with obstructive sleep apnea. Sleep 24:905-909.

Borsini F, Meli A (1988) Is the forced swimming test a suitable model for revealing antidepressants activity? Psychopharmacology 94:147-160.

Borsini F, Lecci A, Sessarego A, Frassine R, Meli A (1989) Discovery of antidepressant activity by forced swimming test may depend on preexposure of rats to a stressful situation. Psychopharmacology 97:183-188.

Chalmers DT, Lovenberg TW, De Souza EB (1995) Localization of novel corticotropin-releasing factor receptor (CRF2) mRNA expression to specific subcortical nuclei in rat brain: comparison with CRF1 receptor mRNA expression. J Neurosci 15:6340-6350.

Chan DW (1992) Coping with depressed mood among Chinese medical students in Hong Kong. J Affect Disord 24:109-116.

Chen Y, Brunson KL, Muller MB, Cariaga W, Baram TZ (2000) Immunocytochemical distribution of corticotropin-releasing hormone receptor type-1 (CRF(1))-like immunoreactivity in the mouse brain: light microscopy analysis using an antibody directed against the C-terminus. J Comp Neurol 420:305-323.

Chrousos GP (2000) Stress, chronic inflammation, and emotional and physical well-being: concurrent effects and chronic sequelae. J Allergy Clin Immunol 106:S275-S291.

Cullinan WE, Helmreich DL, Watson SJ (1996) Fos expression in forebrain afferents to the hypothalamic paraventricular nucleus following swim stress. J Comp Neurol 368:88-99.

Curtis AL, Grigoradis D, Page ME, Rivier J, Valentino RJ (1994) Pharmacological comparison of two corticotropin-releasing factor antagonists: in vivo and in vitro studies. J Pharmacol Exp Ther 268:359-365.

Dallman MF, Akana SF, Scriber KA, Bradbury MJ, Walker CD, Strack AM, Cascio CS (1992) Stress, feedback, and facilitation in the hypothalamopituitary-adrenal axis. J Neuroendocrinol 4:517-526.

De Goeij DCE, Jezova D, Tilders FJH (1992) Repeated stress enhances vasopressin synthesis in corticotropin releasing factor neurons in the paraventricular nucleus. Brain Res 557:265-268.

De Olmos J, Heimer L (1980) Double and triple labeling of neurons with fluorescent substances: the study of collateral pathways in the ascending raphe system. Neurosci Lett 19:7-12.

Detke MJ, Rickels M, Lucki I (1995) Active behaviors in the rat forced swimming test differentially produced by serotonergic and noradrenergic antidepressants. Psychopharmacology 121:66-72.

Dragunow M, Faull RL (1989) The use of c-fos as a metabolic marker in neuronal pathways. J Neurosci Methods 29:261-265.

Duncan GE, Johnson KB, Breese GR (1993) Topographic patterns of brain activity in response to swim stress: assessment by 2-deoxyglucose uptake and expression of fos-like immunoreactivity. J Neurosci 13:3932-3943.

Elenkov IJ, Chrousos GP (1999) Stress, cytokine patterns, and susceptibility to disease. Ballieres Best Pract Res Clin Endocrinol Metab 13:583-595.

Habib KE, Gold PW, Chrousos GP (2001) Neuroendocrinology of stress. Endocrinol Metab Clin North Am 30:695-728.

Hammack SE, Richey KJ, Schmid MJ, LoPresti ML, Watkins LR, Maier SF (2002) The role of corticotropin-releasing hormone in the dorsal raphe nucleus in mediating the behavioral consequences of uncontrollable stress. J Neurosci 22:1020-1026.

Hirschfeld RM, Klerman GL, Clayton PJ, Keller MB (1983) Personality and depression. Empirical findings. Arch Gen Psychiatry 40:993-998.

Imai H, Steindler DA, Kitai ST (1986) The organization of divergent axonal projections from the midbrain raphe nuclei in the rat. J Comp Neurol 243:363-380.

Jacobs BL, Azmitia EC (1992) Structure and function of the brain serotonin system. Physiol Rev 72:165-228.

Kirby LG, Lucki I (1997) Interaction between the forced swimming test and fluoxetine treatment on extracellular 5-HT and 5-HIAA in the rat. J Pharmacol Exp Ther 282:967-976.

Kirby LG, Lucki I (1998) The effect of repeated exposure to forced swimming on extracellular levels of 5-hydroxytryptamine in the rat. Stress 2:251-263.

Kirby LG, Allen AR, Lucki I (1995) Regional differences in the effects of 
forced swimming on extracellular levels of 5-hydroxytryptamine and 5-hydroxyindoleacetic acid. Brain Res 682:189-196.

Kirby LG, Chou-Green JM, Davis K, Lucki I (1997) The effects of different stressors on extracellular 5-hydroxytryptamine and 5-hydroxyindoleacetic acid. Brain Res 760:218-230.

Kirby LG, Rice K, Valentino RJ (2000) Effects of corticotropin-releasing factor on neuronal activity in the serotonergic dorsal raphe nucleus. Neuropsychopharmacology 22:148-162.

Kohler C, Steinbusch H (1982) Identification of serotonin and nonserotonin-containing neurons of the mid-brain raphe projecting to the entorhinal area and the hippocampal formation. A combined immunohistochemical and fluorescent retrograde tracing study in the rat brain. Neuroscience 7:951-975.

Lechner S, Curtis A, Brons R, Valentino R (1997) Locus coeruleus activation by colon distention: role of corticotropin-releasing factor and excitatory amino acids. Brain Res 756:114-124.

Maier SF, Jackson RL (1979) Learned helplessness: all of us were right (and wrong): inescapable shock has multiple effects. Psychol Learn Motiv 13:155-218.

Molliver ME (1987) Serotonergic neuronal systems: what their anatomic organization tells us about function. J Clin Psychopharmacol 7:3S-23S.

Muris P, Schmidt H, Lambrichs R, Meesters C (2001) Protective and vulnerability factors of depression in normal adolescents. Behav Res Ther 39:555-565.

O’Hearn E, Molliver ME (1984) Organization of raphe-cortical projections in rat: a quantitative retrograde study. Brain Res Bull 13:709-726.

Page ME, Berridge CW, Foote SL, Valentino RJ (1993) Corticotropinreleasing factor in the locus coeruleus mediates EEG activation associated with hypotensive stress. Neurosci Lett 164:81-84.

Paxinos G, Watson C (1998) The rat brain in stereotaxic coordinates, Ed 2. North Ryde, Australia: Academic.

Porsolt RD, Le Pinchon M, Jalfre M (1977) Depression: a new animal model sensitive to antidepressant treatments. Nature 266:730-732.

Porsolt RD, Anton G, Blavet N, Jalfre M (1978) Behavioral despair in rats: a new model sensitive to antidepressant treatments. Eur J Pharmacol 47:379-391.

Price ML, Lucki I (2001) Regulation of serotonin release in the lateral sep- tum and striatum by corticotropin-releasing factor. J Neurosci 21:2833-2841.

Price ML, Curtis AL, Kirby LG, Valentino RJ, Lucki I (1998) Effects of corticotropin-releasing factor on brain serotonergic activity. Neuropsychopharmacology 18:492-502.

Price ML, Kirby LG, Valentino RJ, Lucki I (2002) Evidence for corticotropinreleasing factor regulation of serotonin in the lateral septum during acute swim stress: adaptation produced by repeated swim. Psychopharmacology 162:406-414.

Rominger DH, Rominger CM, Fitzgerald LW, Grzanna R, Largent BL, Zaczek $\mathrm{R}$ (1998) Characterization of [ $\left.{ }^{125} \mathrm{I}\right]$ sauvagine binding to $\mathrm{CRH}_{2}$ receptors: membrane homogenate and autoradiographic studies. J Pharmacol Exp Ther 286:459-468.

Snow-Turek AL, Norris MP, Tan G (1996) Active and passive coping strategies in chronic pain patients. Pain 64:455-462.

Tao R, Auerbach SB (2000) Regulation of serotonin release by GABA and excitatory amino acids. J Psychopharmacol 14:100-113.

Thierry B, Steru L, Chermat R, Simon P (1984) Searching-waiting strategy: a candidate for an evolutionary model of depression? Behav Neural Biol 41:180-189.

Valentino RJ, Liouterman L, Van Bockstaele EJ (2001) Evidence for regional heterogeneity in corticotropin-releasing factor interactions in the dorsal raphe nucleus. J Comp Neurol 435:450-463.

Varga V, Szekely AD, Csillag A, Sharp T, Hajos M (2001) Evidence for a role of GABA interneurons in the cortical modulation of midbrain 5-hydroxytryptamine neurones. Neuroscience 106:783-792.

Vertes RP (1991) A PHA-L analysis of ascending projections of the dorsal raphe nucleus in the rat. J Comp Neurol 313:643-668.

Webster EL, Lewis DB, Torpy DJ, Zachman EK, Rice KC, Chrousos GP (1996) In vivo and in vitro characterization of antalarmin, a nonpeptide corticotropin-releasing hormone $(\mathrm{CRH})$ receptor antagonist: suppression of pituitary ACTH release and peripheral inflammation. Endocrinology 137:5747-5749.

Weiss JM, Goodman PA, Losito BG, Corrigan S, Charry JM, Bailey WH (1981) Behavioral depression produced by an uncontrollable stressor: relationship to norepinephrine, dopamine, and serotonin levels in various regions of rat brain. Brain Res Brain Res Rev 3:167-205. 